\title{
SOCIAL MEDIA IN AMERICAN PUBLIC POLICY (ON THE EXAMPLE OF THE SOCIAL NETWORK TWITTER) ${ }^{1}$
}

\author{
Elena V. Efanova \\ Volgograd State University, Volgograd, Russian Federation
}

\begin{abstract}
Introduction. In the age of digitalization of the public space of communication, social media acts as a new channel of interaction between power and society. On the one hand, electronic forms of public communication formulate a political course and influence the political behavior of the electorate, and on the other hand, replace mass communication by a network. Twitter's technological capabilities, being an electronic form of public communication, are addressed by representatives of the political elite in the USA. Methods and materials. The work uses network and communicative approaches, methods of situational analysis. The author addresses statistics and Twitter accounts of American politicians. Analysis. As a result of the computerization and the global spread of the Internet, social media has become an integral part of modern politics. The social network Twitter acts as a new communicative practice in the system of public administration of the USA. For President D. Trump, Twitter is an effective source and platform for presenting his position on domestic and foreign policy issues. Results. Twitter, being an interactive Internet platform based on the principles of network communication, is part of Twitter diplomacy implemented in the United States. The politicization of Twitter in the United States is targeted and ensures the interaction of the highest authorities and the electorate. Twitters functionality is used in modern American politics to shape the image characteristics of individual politicians and the country as a whole.

Key words: communication, Internet, social media, social network, Twitter, public policy, president, USA.

Citation. Efanova E.V. Social Media in American Public Policy (On the Example of the Social Network Twitter). Vestnik Volgogradskogo gosudarstvennogo universiteta. Seriya 4. Istoriya. Regionovedenie. Mezhdunarodnye otnosheniya [Science Journal of Volgograd State University. History. Area Studies. International Relations], 2020, vol. 25, no. 3, pp. 172-179. (in Russian). DOI: https://doi.org/10.15688/jvolsu4.2020.3.15
\end{abstract}

\section{СОЦИАЛЬНЫЕ МЕДИА В АМЕРИКАНСКОЙ ПУБЛИЧНОЙ ПОЛИТИКЕ (НА ПРИМЕРЕ СОЦИАЛЬНОЙ СЕТИ ТWITТЕR) ${ }^{1}$}

\author{
Елена Владимировна Ефанова \\ Волгоградский государственный университет, г. Волгоград, Российская Федерация
}

\begin{abstract}
Аннотация. В условиях становления информационного общества и виртуализации публичного политического пространства граждане получили возможность опосредственного контакта с политикой. В связи с этими тенденциями деятельность политика все чаще предполагает налаживание «связей с общественностью» и применение PR-технологий. В статье доказано, что развитие интернет-технологий и появление социальных медиа повлияли на структуру массовой коммуникации и повлекли за собой изменение коммуника作 ность создавать, хранить и распространять информацию, адресованную широкой аудитории. Установлено, что главными преимуществами социальных медиа по сравнению с традиционными СМИ являются возможность создания аутентичных сообщений, которые позволяют «очеловечить» имидж политика, и ощущения прямого диалога между политиком и аудиторией. В частности, Соединенные Штаты Америки, став первооткрывателем в области цифровой дипломатии, активно развиваются в этой сфере посредством внедрения
\end{abstract}


новых эффективных интернет-ресурсов, улучшения качества взаимодействия простых граждан с ведущими политиками и дипломатами через социальные сети. Президент США Д. Трамп является активным пользователем социальной сети Twitter. Начиная с президентской избирательной компании в 2016 г., Twitter является неотьемлемой частью политики нынешнего американского президента. Иными словами, в современной американской политике социальные медиа выступают в роли нового канала публичной коммуникации.

Ключевые слова: коммуникация, Интернет, социальные медиа, социальная сеть, Twitter, публичная политика, президент, США.

Цитирование. Ефанова Е. В. Социальные медиа в американской публичной политике (на примере социальной сети Twitter) // Вестник Волгоградского государственного университета. Серия 4, История. Регионоведение. Международные отношения. - 2020. - Т. 25, № 3. - C. 172-179. - DOI: https://doi.org/10.15688/ jvolsu4.2020.3.15

Введение. «Интернет-революция» затронула все сферы жизни общества, и начиная с 2000-х гг. в структуре массовой коммуникации активно развивается новый вид коммуникации - социальные медиа, которые во всем своем многообразии (блоги, социальные сети, новостные сайты) замещают массовую коммуникацию сетевой, где производители сообщений контактируют с потребителями, тем самым вовлекая их в дальнейшее распространение этих сообщений. Все это наделяет социальные медиа управленческим потенциалом. Они могут рассматриваться в качестве инструмента политического влияния, и особую ценность социальные медиа представляют для политического пиара. Более того, социальные медиа активно развиваются в техническом плане, а их аудитория постоянно растет. Так, социальная сеть Twitter как один из видов социальных медиа демонстрирует широкую популярность в американском истеблишменте. Президент США Д. Трамп, как и его предшественник Б. Обама, обращается к технологическим возможностям Twitter как электронной формы публичной коммуникации с целью формулирования политического курса и оказания влияния на политическое поведение электората.

Кроме того, интересен тот факт, что помимо Twitter-страницы Д. Трампа институты и отдельные представители государственной власти США имеют свои аккаунты. В частности, в социальной сети есть страница Белого дома (@WhiteHouse), Совета национальной безопасности США (@WHNSC), вицепрезидента США Майка Пенса (@VP), госсекретарь Майка Помпео (@SecPompeopew). Тем не менее вышеперечисленные страницы содержат лишь официальные заявления того или иного органа государственной власти, которые не несут эмоциональной окраски, или репосты с личной страницы Д. Трампа. Поэтому аккаунт и публикуемые на его платформе твиты нынешнего президента США, которые с 2017 г. считаются официальными заявлениями, служат реальным источником осуществляемой в США Twitter-дипломатии.

Методы и материалы. В качестве методологической базы исследования выступает сетевой подход (М. Кастельс), позволивший выявить специфику отношений между акторами политики в рамках динамически развивающегося сетевого онлайн-пространства, а также принципы коммуникативного подхода (К. Дойч). В работе использован метод ситуационного анализа. Материалы аналитических ведомств характеризуют состояние и тенденции развития современного медиапространства. Данные Twitter-аккаунтов раскрывают особенности цифровой дипломатии США.

Анализ. Для политической сферы социальные медиа стали новым каналом политической коммуникации, который имеет свои возможности и свою специфику. Социальные медиа, аудитория которых постоянно растет, обладают огромным потенциалом для PR-активности крупнейших политических сил. Тем самым пространство социальных медиа становится новым полем информационной борьбы политических деятелей за внимание и доверие избирателей.

В начале XXI в. повсеместная компьютеризация и глобальное распространение Интернета привели к тому, что многие граждане получили доступ к тем же инструментам, что и профессиональные производители новостей. В это же время появляются социальные ме- 
диа, которые стали платформой, где различные люди могли сами создавать и распространять свои сообщения [1, с. 610].

Так, оценивая современную конфигурацию эволюционирующего медиапространства, целесообразно обратиться к статистическим данным глобального агентства «We Are Social» [12], согласно которым количество интернет-пользователей на начало 2020 г. достигло 4,54 млрд чел. при народонаселении 7,75 млрд чел., а аудитория социальных медиа составляла 3,80 млрд человек.

Социальные медиа представляют собой особую разновидность СМИ и обладают характерными чертами, среди которых - возможность корректировки публикуемой информации, интерактивность, возможность отслеживать популярность сообщения, доступность старых материалов, мультимедийность, ссылки на другие материалы и неполный контроль за содержанием страницы [2, с. 228]. В общем смысле социальные медиа представляют интерактивные многопользовательские сайты, где пользователи сами формируют общий контент, то есть «сайт представляет собой автоматизированную социальную среду, позволяющую общаться группе пользователей, объединенных общим интересом» [3, с. 245].

Заметим, что распространение сообщений в социальных медиа носит не хаотичный характер, а, наоборот, строго структурированный. Сообщения, которые распространяют пользователи, отмеченные как «друзья», формируют поток сообщений, называемый «лентой новостей». «Лента новостей» является центральным элементом любой социальной сети. Также необходимо отметить, что информация в социальных медиа представлена как в визуальной, так и в текстовой форме. Обширный функционал социальных медиа позволяет моментально загрузить фотографию или видеофайл на страницу, который сразу же отобразится в «ленте новостей».

Американский исследователь Б. Солис акцентирует внимание на технологической природе социальных медиа. По его мнению, «социальные медиа в самом общем виде это способ, при помощи которого люди обнаруживают, читают и комментируют новости, информацию и содержание. Это слияние социальной составляющей и высоких техноло- гий, трансформирующих монолог (от одного ко многим) в диалог (многие ко многим)» [16, p. 19]. То есть пользователи социальных медиа, устанавливая взаимосвязи друг с другом и различными сообществами, формируют определенную сеть. Внутри этой сети разворачивается вся коммуникация: пользователи сами создают и редактируют сообщения, распространяя их по всей сети между «друзьями». Число получателей этих сообщений может быть ограничено одним человеком или составлять множество людей, которые также являются производителями сообщений. Иными словами, коммуникация в социальных медиа представляет собой новый вид коммуникации или, по мысли М. Кастельса, новую форму массовой самокоммуникации. Коммуникация в социальных медиа потенциально может достичь глобальной аудитории посредством массовой рассылки сообщения и распространения по сети. В то же время производство сообщений осуществляется самостоятельно каждым пользователем, так же как и другие действия, например поиск получателя сообщения [5, с. 74].

Такие сети коммуникации характеризуются открытостью, децентрализованностью, преобладанием горизонтальных связей, саморазвитием, автономностью включенных в них узлов. Именно эти свойства позволяют эффективно работать с информацией в социальных медиа [11, p. 13]. Коммуникационные сети не содержат ничего, кроме связей и узлов. Связи подразумевают взаимодействие между пользователями сети и обмен информацией, а узлы - это пользователи. Появление устойчивых связей между узлами выступает необходимым условием для соединения отдельных пользователей в единую сеть. Главная особенность данной сети заключается в возможности выстраивания одновременного взаимодействия множества таких узлов. Таким образом, социальные медиа обладают собственной спецификой и особым коммуникационным потенциалом, поэтому использование политическими субъектами социальных медиа для достижения своих целей становится неизбежным.

Возможности социальных медиа создают иллюзию прямого контакта между политиком и электоратом, позволяют общаться с 
представителями целевых аудиторий и получать от них обратную связь. Благодаря возможностям коммуникационной сети, пользователи сами распространяют идеи и сообщения, принимаемые от политического лидера, среди своего окружения.

Социальные медиа заметно изменили коммуникативные практики в современном обществе. Они стали новым высокотехнологичным и вседоступным инструментом формирования социального капитала политика и продвижения его имиджа в общественном сознании. На современном этапе социальные медиа являются одним из важнейших ресурсов информационного влияния, активизируя общественное мнение и электоральное поведение, консолидируя общественность и формируя отношение доверия между политиком и обществом [6, с. 77].

Изменение коммуникативных практик и развитие социальных медиа повлекли за собой изменения в сфере политических связей с общественностью. Политический PR в социальных медиа стал смещаться в сторону непосредственного общения с электоратом. Политики и имиджмейкеры получили возможность отслеживать мнение электората о политике в реальном времени, внедряться в интернет-сообщества для распространения необходимой информации и влиять на мнение электората, используя более привлекательные для аудитории каналы (видео, фото, ссылки, подкасты). К основным направлениям политического PR в социальных медиа стоит отнести оптимизацию официальных страниц лидеров политических партий под поисковые системы, создание дискуссий в блогосфере, размещение пресс-релизов, взаимодействие с сетевыми СМИ, проведение онлайн-конференций, создание подкастов, видео и их рассылка и т. д. [2, с. 230].

Социальная сеть Twitter является особой разновидностью социальных медиа, используемой правительствами и ведомствами для реализации своих целей в политике. По состоянию на апрель 2016 г. в Twitter было в общей сложности 793 аккаунта, принадлежащих политическим лидерам 173 стран. Таким образом, $90 \%$ стран - участниц ООН представлены в Twitter, охватывая аудиторию 324 миллиона подписчиков. Только 20 стран, главным образом из Тихоокеанского региона и Африки, не имеют каких-либо учетных записей в Twitter. Даже правительство Китая, блокирующее на территории своей страны социальные медиа западных стран, медленными темпами идет в сторону большей вовлеченности в социальные сети, и некоторые из дипломатических представителей Китая активно взаимодействуют с публикой путем использования Twitter [15].

Считается, что политизация данной социальной сети началась в 2007 г., когда там зарегистрировался Барак Обама с целью всестороннего охвата аудитории во время своей первой предвыборной кампании. Помимо личной страницы Б. Обамы, в июне 2013 г. был зарегистрирован аккаунт @POTUS (President of the United States), который стал специальной учетной записью, созданной для президента США. Интересен тот факт, что доступ к этой странице Б. Обама получил только в 2015 г., хотя его второй строк президентства начался в 2012 г. и продлился до 2017 года. В основном данные аккаунты содержали лишь ретвиты и ответы на вопросы, а также официальные заявления президента. Кроме того, многие из опубликованных твитов были написаны не лично Б. Обамой [3, с. 246]. Таким образом, в период двух президентских сроков Б. Обама использовал Twitter лишь для контента информационного характера, то есть для того, чтобы широкая общественность имела открытый доступ к ресурсам, непосредственно касающимся процесса принятия политических решений и проводимой политики в США.

Единственной прорывной идеей в сфере социальных сетей во второй президентский срок Б. Обамы стало использование Twitter как мощного и эффективного инструмента создания политических протестов нового типа. Так, в 2011 г. в странах Северной Африки вспыхнули восстания, результатом которых стало изгнание президентов в Египте, Йемене и Ливии; массовые беспорядки наблюдались на Ближнем Востоке, волнения были зафиксированы в Соединенных Штатах и Испании. Новшеством во всех раннее указанных волнениях стало использование социальных медиапрограмм и интернет-платформ, явившихся источником отражения попыток подавления протеста, а также способом коммуницирования в среде проте- 
стующих. «Арабская весна» стала известна также как «сетевая революция» или «вирусная сетевая технология» [4].

В частности, в период с 2010 по 2011 г. мировое сообщество осознало, какую огромную роль социальные сети могут играть в организации массовых беспорядков, революций и государственных переворотов, которые охватили множество стран Ближнего Востока и Северной Африки.

Следует отметить, что впервые события «арабской весны» вспыхнули в Тунисе, который занимал лидирующие позиции среди стран Северной Африки по числу пользователей сети Интернет. Социальные сети оппозиция взяла под свой контроль и использовала для координации действий протестующих, призывов к решительным действиям, а также к смене политического режима, к чему и привели данные события. В частности, активисты с площади Тахрир активно использовали хештеги \#Jan25 и \#tahrir, призывая молодых людей к мобилизации. Таким образом, социальные сети, в том числе и Twitter, стали новым форматом политического участия: многие пользователи самостоятельно создавали новые аккаунты и группы для подготовки митингов с требованиями отставки президента страны. В результате социальные сети выступили как единый организатор революционных настроений среди граждан арабских стран и как объединяющая сила против власти. Позже данные события стали назваться «твиттерными революциями» [7, с. 123].

Однако, как считают многие современные аналитики, настоящий прорыв в использовании социальной сети Twitter как политического инструмента совершил нынешний президент США Дональд Трамп. Он начал использовать свою личную страницу в качестве площадки для предоставления идей и информации, причем не только во время предвыборной гонки, но и после избрания его президентом.

Д. Трамп значительно изменил коммуникацию политической элиты, перевернув представление о роли социальных сетей в сфере политики. С приходом нового президента к власти возникло понятие «Twitter-дипломатия», которое приобрело негативную коннотацию и ассоциируется с отсутствием серьез- ного подхода к решению политических проблем. Тем не менее для Д. Трампа Twitter стал одним из основных инструментов реализации его политики, как внутренней, так и внешней.

Д. Трамп пользуется двумя аккаунтами в Twitter - официальным (@POTUS) и личным (@realDonaldTrump). По заявлению Белого дома в июне 2017 г., твиты Д. Трампа на личной странице @realDonaldTrump считаются официальными заявлениями президента США [8, с. 396]. Однако иные СМИ Д. Трамп все же поддерживает. Зачастую он излагает мнения и делится (делает ретвит) статьями, которые отвечают его убеждениям (некоторые публикации заимствуются с ресурсов «Washington Post» и «Daily Mail» [13]).

Госс екретарь США Майк Помпео называет сообщения Д. Трампа в Twitter «невероятно эффективным средством коммуникации»: «Я хорошо знаю президента Трампа... Я наблюдаю, как он доносит информацию. В былые времена это делалось посредством заявлений для прессы, пресс-релизов или же кто-то давал пресс-конференцию с трибуны в Западном крыле Белого дома. Президент Трамп делает это посредством Twitter. Таким образом, он может донести свои мысли до всего мира в один миг. Это невероятно эффективное средство общения» [9]. Кроме того, госсекретарь США не раз утверждал, что осуществляемая Twitter-дипломатия является оперативным источником для влияния на информационное поле действий, во многом потому, что мировые лидеры быстро реагируют на публикуемые в социальной сети твиты.

Помимо М. Помпео свое мнение о явлении Twitter выражает и пресс-секретарь Белого дома Сара Сандерс (до 1 июля 2019 г.). В частности, она отмечает, что твиты для Д. Трампа - это способ выражать напрямую, без фильтров, мнение своим последователям. При этом советник президента Келлиэн Конуэй называет одержимостью СМИ тот факт, что они много времени уделяют освещению сообщений Д. Трампа в Twitter вместо того, чтобы сконцентрироваться на том, какие действия он совершает в качестве президента [10].

В июле 2017 г., когда Д. Трамп официально стал президентом Соединенных Шта- 
тов Америки, он заявил, что не намерен прекращать делать записи в Twitter, несмотря на многочисленные призывы со стороны конгресca, а также СМИ. Президент также выразил свое мнение и в Twitter: «Это мой голос... им не заставить меня прекратить использовать социальные сети» [14]. Кроме того, сам президент называет свою модель ведения политики посредством социальных сетей стилем работы «президента сегодняшнего дня».

Следует отметить, что для Д. Трампа Twitter является наиболее эффективным источником и платформой для представления своей позиции по ряду важнейших экономических, политических и социальных вопросов. Это также и средство информирования аудитории и формирования общественного мнения, площадка для дискуссий со своими оппонентами и механизм самопрезентации, конструирования действительности, отражение реальности через свое собственное видение. Самопрезентация, или самореклама, является основной особенностью личного аккаунта президента США. Цель Д. Трампа показать себя в лучшем свете достигается при помощи таких приемов, как восхваление своей политической деятельности, подчеркивание собственных достоинств, сравнение с деятельностью американских президентов-предшественников и президентов других стран мира.

Результаты. Появление социальных медиа повлекло за собой изменение коммуникативных практик между субъектами политики. С точки зрения коммуникативного подхода социальные медиа - это интерактивные интернет-платформы, основанные на принципах сетевой коммуникации, где любой пользователь получает возможность создавать, хранить и распространять информацию, адресованную широкой аудитории. Социальные медиа представляют новый вид коммуникации, называемый самокоммуникацией или сетевой коммуникацией, где каждый участник может одновременно выступать в роли производителя и получателя сообщений. Коммуникация в таких медиа, благодаря использованию новых информационных технологий, образует сеть взаимосвязанных узлов и основывается на принципах автономности, саморазвития, децентрализованности и преобладания горизонтальных связей. Создание дискуссий в блогосфере, размещение прессрелизов, взаимодействие с сетевыми СМИ, проведение онлайн-конференций, создание подкастов, видео и их рассылка, организация мероприятий, проведение офлайн-встреч все это выступает в роли приемов сетевого взаимодействия современного политика и электората.

Широкий спектр функциональных возможностей социальных сетей способствует открытой информационной деятельности современных государств. С приходом на пост президента Д. Трампа позиция Америки по актуальным вопросам внутренней и внешней политики стала отражаться не только в официальных заявлениях Белого дома и нормативных документах, но и на личной странице президента в Twitter, что, в свою очередь, стало частью реализуемой в США Twitter-дипломатии. Очевидно, что посредством социальной сети Twitter Д. Трамп решает как внутриполитические (формирование позитивного имиджа в глазах электората), так и внешнеполитические задачи (улучшение образа своей страны, распространение своих ценностей за рубежом, развитие международного сотрудничества).

\section{ПРИМЕЧАНИЕ}

${ }^{1}$ Исследование выполнено при финансовой поддержке РФФИ и Администрации Волгоградской области в рамках научного проекта № 19-411340006 «Социально-политическое проектирование публичного пространства и системы массовой коммуникации в регионах РФ (на примере Волгоградской области)».

The reported study was funded by RFBR and the government of Volgograd region according to the research project No. 19-411-340006 "Socio-political design of public space and mass communication system in the regions of the Russian Federation (the example of the Volgograd region)".

\section{СПИСОК ЛИТЕРАТУРЫ}

1. Балуев, Д. Г. Политическая роль социальных медиа как поле научного исследования / Д. Г. Балуев // Образовательные технологии и общество. 2013. - № 2. - С. 604-616.

2. Быков, И. А. Технология Веб 2.0 и связи с общественностью: смена парадигмы или дополни- 
тельные возможности? / И. А. Быков, О. Г. Филатова // Вестник Санкт-Петербургского университета. Серия 9, Филология. Востоковедение. Журналистика. -2011 . - № 2. - С. 226-237.

3. Ефимова, И. Н. Социальные сети как новый механизм формирования имиджа субъектов политической деятельности / И. Н. Ефимова, А. В. Маковейчук // Известия Алтайского государственного университета. - 2017. - № 4-1 (76). - С. 245-248.

4. Ильичева, Ю. А. Мобилизационные технологии: сущность, предпосылки возникновения, основные инструменты и средства / Ю. А. Ильичева // Медиаскоп. - 2013. - № 2. - Электрон. текстовые дан. Режим доступа: http://www.mediascope.ru/node/1335 (дата обращения: 01.04.2019). - Загл. с экрана.

5. Кастельс, М. Власть коммуникации / М. Кастельс. - М. : ГУ ВШЭ, 2016. - 564 с.

6. Рыхтик, М. И. Роль социальных медиа в реализации имиджевых стратегий политических деятелей в контексте формирования информационного общества на региональном уровне / М. И. Рыхтик, А. В. Маковейчук // Вопросы управления. 2015. - № 6 (18). - С. 76-82.

7. Торочкова, П. А. Социальные сети как элемент информационных технологий - новый актор мировой политики / П. А. Торочкова // Вестник Российского государственного гуманитарного университета. Серия: Политология. История. Международные отношения. - 2014. - № 7 (129). - С. 116-126.

8. Харламова, Т. В. Социальные сети как инструмент современной политической власти (на материале микроблога Д. Трампа в Твиттере) / Т. В. Харамова // Известия Саратовского университета. Новая серия. Серия: Филология. Журналистика. - 2018. T. 18, № 4. - С. 396-402.

9. Таран, И. «Элемент информационной войны»: как Twitter-дипломатия Трампа влияет на международную политику / И. Таран, А. Медведева // RT на русском. - 2019. - Электрон. текстовые дан. Режим доступа: https://russian.rt.com/world/article/ 686383-ssha-tramp-pompeo-twitter-diplomatiya (дата обращения: 30.11.2019). - Загл. с экрана.

10. Buncombe, A. Kellyanne Conway Says Media Is "Obsessed" with Trump's Tweets After President Goes on Early Morning Tirade / A. Buncombe. Electronic text data. - Mode of access: https:// www.independent.co.uk/news/world/americas/uspolitics/trump-travel-ban-tweets-kellyanne-conwaymedia-obsessed-twitter-president-a 7773726.html (date of access: 01.04.2019). - Title from screen.

11. Castells, M. The Internet Galaxy: Reflections on the Internet, Business, and Society / M. Castells. Oxford : Oxford University Press, 2001. - 292 p.

12. Digital in 2020. - Electronic text data. - Mode of access: https://wearesocial.com/digital-2020 (date of access: 30.03 .2020$)$. - Title from screen.
13. Graham, J. Trump vs. Clinton: How the Rivals Rank on Twitter, Facebook, More / J. Graham. Electronic text data. - Mode of access: https:// www.usatoday.com/story/tech/news/2016/08/04/ trump-clinton-social-media-twitter-facobook-youtubesnapchat/87974630 (date of access: 05.04.2019). - Title from screen.

14. Leibovich, M. This Town Melts Down / M. Leibovich // The New York Times Magazine. Electronic text data. - Mode of access: https:// www.nytimes.com/2017/07/11/magazine/washingtondc-politics-trump-this-town-melts-down.html?_r= 0\&mtrref-www.axios.com (date of access: 30.03 .2019 ). Title from screen.

15. Lüfkens, M. Twiplomacy Study 2017 / M. Lüfkens. - Electronic text data. - Mode of access: https://wiplomacy.com/blog/twiplomacy-study-2017 (date of access: 30.03.2019). - Title from screen.

16. Solis, B. Putting the Public Back in Public Relations: How Social Media Is Reinventing the Aging Business of PR / B. Solis, D. Breakenridge. - Upper Saddle River : Pearson Education Inc., 2009. - 352 p.

\section{REFERENCES}

1. Baluev D.G. Politicheskaya rol sotsialnykh media kak pole nauchnogo issledovaniya [The Political Role of Social Media as a Field of Scientific Research]. Obrazovatelnye tekhnologii $i$ obshchestvo [Educational Technology \& Society], 2013, no. 2, pp. 604-616.

2. Bykov I.A., Filatova O.G. Tekhnologiya Veb 2.0 i svyazi s obshchestvennostyu: smena paradigmy ili dopolnitelnye vozmozhnosti? [Web 2.0 and Public Relations Technology: Paradigm Shift or Additional Capabilities?]. Vestnik Sankt-Peterburgskogo universiteta. Seriya 9. Filologiya. Vostokovedenie. Zhurnalistika [Vestnik of St. Petersburg State University. Series 9, Philology, Asian Studies, Journalism], 2011, no. 2, pp. 226-237.

3. Efimova I.N., Makoveychuk A.V. Sotsialnye seti kak novyy mekhanizm formirovaniya imidzha subyektov politicheskoy deyatelnosti [Social Networks as a New Mechanism for Shaping the Image of Political Actors]. Izvestiya Altayskogo gosudarstvennogo universiteta [Izvestiya of Altai State University Journal], 2017, no. 4-1 (76), pp. 245-248.

4. Ilicheva Yu. A. Mobilizatsionnye tekhnologii: sushchnost, predposylki vozniknoveniya, osnovnye instrumenty i sredstva [Mobilization Technologies: Essence, Prerequisites, Basic Tools and Means]. Mediaskop [Mediascope], 2013, no. 2. URL: http:// www.mediascope.ru/node/1335 (accessed 1 April 2019).

5. Kastels M. Vlast kommunikatsii [Power of Communication]. Moscow, GUVShE, 2016. 564 p. 
6. Rykhtik M.I., Makoveychuk A.V. Rol sotsialnykh media $\mathrm{v}$ realizatsii imidzhevykh strategiy politicheskikh deyateley $\mathrm{v}$ kontekste formirovaniya informatsionnogo obshchestva na regionalnom urovne [Role of Social Media in the Implementation of Image Strategies of Politicians in the Context of the Formation of the Information Society at the Regional Level]. Voprosy upravleniya [Management Issues], 2015, no. 6 (18), pp. 76-82.

7. Torochkova P.A. Sotsialnye seti kak element informatsionnykh tekhnologiy - novyy aktor mirovoy politiki [Social Networks as an Element of Information Technology - A New Actor of World Politics]. Vestnik Rossiyskogo gosudarstvennogo gumanitarnogo universiteta. Seriya: Politologiya. Istoriya. Mezhdunarodnye otnosheniya [RSUH/RGGU Bulletin Series "Political Science. History. International Relations"], 2014, no. 7 (129), pp. 116-126.

8. Kharlamova T.V. Sotsialnye seti kak instrument sovremennoy politicheskoy vlasti (na materiale mikrobloga D. Trampa v Tvittere) [Social Media as a Tool of Modern Political Power (on D. Trumps Twitter Microblog)]. Izvestiya Saratovskogo universiteta. Novaya seriya. Seriya: Filologiya. Zhurnalistika [Izvestiya of Saratov University. New Series. Series: Philology. Journalism], 2018, vol. 18, no. 4, pp. 396-402.

9. Taran I., Medvedeva A. «Element informatsionnoy voyny»: kak Twitter-diplomatiya Trampa vliyaet na mezhdunarodnuyu politiku ["Information War Element": How Trumps Twitter Diplomacy Affects International Politics]. $R T n a$ russkom. [RT in Russian.], 2019. URL: https:// russian.rt.com/world/article/686383-ssha-tramppompeo-twitter-diplomatiya (accessed 30 November 2019).

10. Buncombe A. Kellyanne Conway Says Media Is "Obsessed" with Trumps Tweets After President Goes on Early Morning Tirade. URL: https:/ /www.independent.co.uk/news/world/americas/uspolitics/trump-travel-ban-tweets-kellyanne-conwaymedia-obsessed-twitter-president-a7773726.html (accessed 1 April 2019)

11. Castells M. The Internet Galaxy: Reflections on the Internet, Business, and Society. Oxford, Oxford University Press, 2001. 292 p.

12. Digital in 2020. URL: https://wearesocial. com/digital-2020 (accessed 30 March 2020).

13. Graham J. Trump vs. Clinton: How the Rivals Rank on Twitter, Facebook, More. URL: https:// www.usatoday.com/story/tech/news/2016/08/04/ trump-clinton-social-media-twitter-facobook-youtubesnapchat/87974630 (accessed 5 April 2020).

14. Leibovich M. This Town Melts Down. The New York Times Magazine. URL: https://www.nytimes.com/ 2017/07/11/magazine/washington-dc-politics-trump-thistown-melts-down.html?_r=0\&mtrref=www.axios.com (accessed 30 March 2019).

15. Lüfkens M. Twiplomacy Study 2017. URL: https://wiplomacy.com/blog/twiplomacy-study-2017 (accessed 30 March 2019).

16. Solis B., Breakenridge D. Putting the Public Back in Public Relations: How Social Media Is Reinventing the Aging Business of PR. Upper Saddle River, Pearson Education Inc., 2009. 352 p.

\section{Information About the Author}

Elena V. Efanova, Candidate of Sciences (Politics), Associate Professor, Department of International Relations, Political Science and Area Studies, Volgograd State University, Prosp. Universitetsky, 100, 400062 Volgograd, Russian Federation, efanova@volsu.ru, https://orcid.org/0000-0003-2019-1273

\section{Информация об авторе}

Елена Владимировна Ефанова, кандидат политических наук, доцент кафедры международных отношений, политологии и регионоведения, Волгоградский государственный университет, просп. Университетский, 100, 400062 г. Волгоград, Российская Федерация, efanova@volsu.ru, https://orcid.org/0000-0003-2019-1273 